alle von den IgE-Antikörpern der Kinder mit persistierender Allergie erkannt wurden. Die IgE-Antikörper von Kindern mit temporärer Allergie erkannten dagegen keine dieser Bindungsstellen.

Diese unterschiedliche Epitopspezifität weist auf unterschiedliche Sensibilisierungsmuster hin: Bei vielen Kleinkindern lassen sich nach einer Mahlzeit Nahrungsmittelproteine im Blut nachweisen, bedingt durch die Unreife des Verdauungstrakts mit herabgesetzter Verdauungsarbeit und einer erhöhten Durchlässigkeit der Darmbarriere. Genetisch vorbelastete Kinder werden in den frühen Phasen ihres Lebens auf diese Weise vor allem gegen native Hühnereiallergene sensibilisiert, verlieren ihre Allergie aber mit zunehmender Reife des Verdauungssystems oder bei stringenter Meidung von Eiern. Kinder mit einer Sensibilisierung vor allem gegen die linearen Epitope, in denen die Aminosäuren direkt nebeneinander liegen, können mit diesen Epitopen aber auch bei Zufuhr von denaturiertem Eiweiß konfrontiert werden: Die linearen Epi-

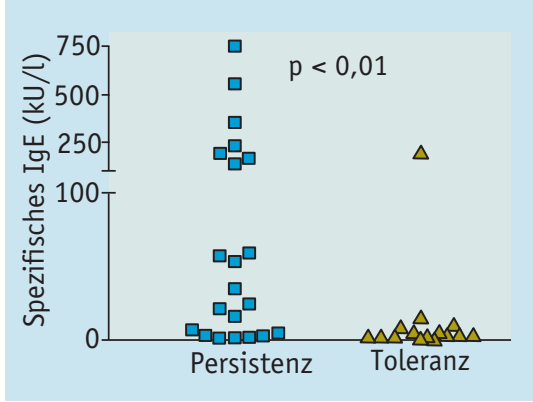

Kinder mit persistierender Hühereiweißallergie weisen mehr spezifisches IgE gegen Ovomucoid auf als Kinder, die mit den Jahren tolerant werden.

\title{
Sesam ist hartnäckig
}

\section{Nahrungsmittelallergien spiegeln auch regionale Ernährungs- gewohnheiten wider. Im nahen Osten spielt Sesam dabei eine wichtige Rolle.}

E ine israelische Kohortenstudie untersuchte an 74 Patienten mit einer Sensibilisierung gegen Sesam die Entwicklung von Sesamallergien in der Kindheit. Basis waren anamnestische Daten, ergänzt um eine aktuelle Befragung, sowie Pricktests, Bestimmung des spezifischen Serum-IgE und orale Provokationstests. Nach der klinischen Ausprägung unterschieden die Untersucher Kinder mit allergischen Reaktionen nach sesamhaltiger Nahrung $(n=45)$, Kinder mit einer atopischen Dermatitis und einer Reaktion gegen Sesam im Pricktest $(\mathrm{n}=11)$ und solche, die nur in der Blutuntersuchung eine Sensibilisierung für Sesam aufwiesen $(\mathrm{n}=18)$.

Drei Viertel der Probanden, die auf orale Sesamaufnahme Symptome entwickelten, hatten diese Reaktionen schon sehr früh ausgebildet, im Median bereits im Alter von einem Jahr. Meist handelte es sich um eine Reaktion vom Soforttyp auf geringste Mengen von Sesam. Typische auslösende Nahrungsmittel waren die in der israelischen wie arabischen Küche häufige Tahina (Sesampaste) oder auch Halva (eine Süßspeise). Fast alle Patienten zeigten Hautsymptome $(98 \%)$, mehr als die Hälfte Atemwegssymptome (58\%) und jeder Dritte gastrointestinale Reaktionen (33\%). Bei oraler Provokation reagier-

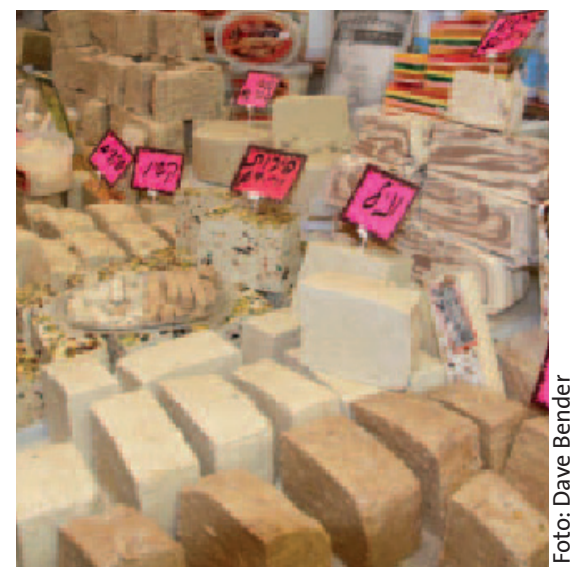

Sesamhaltige Gerichte wie Halva werden im Nahen Osten aufgrund ihres hohen Nährwerts bereits nach wenigen Lebensmonaten zugefüttert. tope werden in Form von kleinen Eiweißfragmenten auch in höherem Alter durch die Darmschleimhaut resorbiert und führen dadurch zu einer fortgesetzten spezifischen IgE-Produktion.

Fazit: Patienten mit einer persistierenden Hühnereiallergie haben deutlich erhöhte Konzentrationen von IgE-Antikörpern gegen sequenzielle und native Epitope der beiden Hauptallergene Ovomucoid und Ovalbumin. IgE-Antikörper speziell gegen sequenzielle Epitope von Ovomucoid könnten als Marker für eine persistierende Allergie herangezogen werden.

$b k$

Järvinen KM et al. Specificity of IgE antibodies to sequential epitopes of hen's egg ovomucoid as a marker for persistence of egg allergy. Allergy 2007; 62: 758-65 ten $88 \%$ von 16 Getesteten. In der medianen Nachbeobachtungszeit von 6,4 Jahren hatte nur jeder Fünfte eine Toleranz ausgebildet.

Bei drei von vier Patienten mit atopischer Dermatitis und positivem Pricktest auf Sesam ergab der Hauttest Hinweise auf weitere Nahrungsmittelsensibilisierungen. Eine Soforttypreaktion wurde in dieser Gruppe allerdings nicht berichtet.

Symptomlose Patienten mit spezifischem IgE gegen Sesam im Serum reagierten nur in seltenen Fällen auch im Pricktest auf Sesam.

Zwischen Quaddelgröße im Pricktest und Konzentration an spezifischem Serum-IgE, Ergebnis der oralen Provokation und einer Toleranzentwicklung bestand kein Zusammenhang.

Fazit: Sesamallergie tritt im Nahen Osten verbreitet auf - aufgrund der Ernährungsgewohnheiten auch schon in den ersten Lebensmonaten. Meist tritt keine Toleranzentwicklung ein. Die Diagnose kann ausreichend gut durch Anamnese und Pricktestung gestellt werden. $\quad f k$

Cohen A et al. Sesame food allergy and sensitization in children: the natural history and long-term follow-up. Pediatr Allergy Immunol 2007; 18: 217-23 